\title{
MAPEAMENTO DA FRAGILIDADE AMBIENTAL NO TRECHO DE VAZÃO REDUZIDA DO RIO ARAGUARI (MG) COM TÉCNICAS DE GEOPROCESSAMENTO
}

\author{
Silvio Carlos Rodrigues* \\ Nilton César de Souza**
}

Resumo: Os estudos de fragilidade ambiental são instrumentos que auxiliam os planejadores e gestores tomarem decisões que garantam um manejo adequado do meio ambiente, pois permitem avaliar as potencialidades do meio ambiente de forma integrada. Baseando-se na metodologia da fragilidade empírica proposta por Ross (1994) foram realizados mapas de fragilidade ambiental da bacia afluente do Trecho de Vazão Reduzida do Rio Araguari nos anos de 1979, 1999 e 2009, utilizando técnicas de geoprocessamento. Com os produtos cartográficos de síntese foi possível constatar que a ação antrópica é a responsável pela alteração da fragilidade ambiental no período analisado, pois as alterações de padrão do uso da terra criadas pela ação humana, interferem diretamente na fragilidade da paisagem, gerando áreas com maior propensão a degradação ambiental.

Palavras-chave: fragilidade ambiental, planejamento, SIG, zoneamento, mapas temáticos.

\section{MAPPING THE ENVIRONMENTAL FRAGILITY IN ARAGUARI RIVER (MG) USING GEOPROCESSING TECHNIQUES}

\begin{abstract}
Studies of environmental fragility are tools to aid planners and managers make decisions that ensure an adequate management of the environment because they allow evaluating the potential of the environment in an integrated manner. Based on the empirical methodology to evaluate environmental fragility proposed by Ross (1994) maps of environmental fragility of the basin tributary of Reduced Flow Channel of Araguari River in the years 1979, 1999 and 2009 were made using GIS techniques. Using the synthesis cartographic products was possible to demonstrate that human action is responsible for the alteration of environmental fragility in the period analyzed, because changes in land use pattern created by human action, directly interferes with the fragility of the landscape, generating areas with the highest propensity to environmental degradation
\end{abstract}

Keywords: environmental fragility, planning, GIS, zoning, thematic maps.

\section{Introdução}

O uso antrópico da Bacia Hidrográfica do Rio Araguari (MG) requer estudos e medidas que garantam a perenidade dos seus recursos naturais renováveis e de seus processos ecológicos, mantendo sua biodiversidade e um meio ambiente ecologicamente equilibrado.

O mapa de fragilidade ambiental é uma ferramenta que auxilia os planejadores e gestores tomarem decisões que assegurem um manejo adequado do meio ambiente. O mapeamento da fragilidade ambiental permite avaliar as potencialidades do meio ambiente de forma integrada.

$$
\text { Baseando-se na metodologia da }
$$
fragilidade empírica proposta por Ross (1994) foram realizados estudos básicos do relevo, geologia, uso da terra e cobertura vegetal. Essas informações foram analisadas de forma integrada gerando um produto síntese que

\footnotetext{
* Professor doutor do Instituto de Geografia da UFU. E-mail: silgel@ufu.br.

** Geógrafo pelo Instituto de Geografia da UFU. E-mail: ncesar@famev.ufu.br.
} 
expressa os diferentes graus de fragilidade que o ambiente possui em função de suas características.

A área de estudos corresponde a um trecho do Rio Araguari que, devido às suas características morfológicas favoráveis, teve o seu potencial hídrico aproveitado com a construção de Usinas Hidrelétricas.

O presente trabalho tem como objetivo mapear a fragilidade ambiental da bacia afluente do Trecho de Vazão Reduzida do Rio Araguari nos anos de 1979, 1999 e 2009, utilizando técnicas de geoprocessamento.

\section{Referencial teórico}

A atmosfera, a hidrosfera, a litosfera e a biosfera são componentes da natureza que se articulam e se interagem, formando mecanismos complexos de funcionamento e de interdependência. Baseando-se nessa interdependência e no conceito de Unidades Ecodinâmicas preconizadas por Tricart (1977), o ambiente pode ser analisado sob o prisma da Teoria de Sistemas que considera que na natureza as trocas de energia e matéria se processam através de relações de equilíbrio dinâmico. O sistema apresenta propriedades que lhe são inerentes e diferem da soma das propriedades dos seus componentes.

A adoção do conceito de sistema pela ecologia permitiu integrar conhecimentos, chegando numa visão de conjunto, sem, contudo, deixar a análise e a investigação.
A troca permanente de energia e matéria que se processa nos ambientes naturais, aliada a presença da água em seus três estados físicos, é a responsável pela dinâmica e pela presença da vida na terra. (ROSS, 1994)

Os ambientes naturais possuem um estado de equilíbrio dinâmico que pode ser rompido com a intervenção do homem. De acordo com Tricart (1977) "a gestão dos recursos ecológicos deve ter por objetivo a avaliação da inserção da tecnologia humana no ecossistema".

Os estudos integrados de um determinado território devem buscar a síntese do conhecimento acerca da realidade pesquisada. Segundo Ross (1994), o conhecimento das potencialidades dos recursos naturais passa pelos levantamentos de todas as componentes do estrato geográfico que dão suporte a vida animal e do homem. Entretanto deve-se considerar o princípio de que a natureza apresenta funcionalidade intrínseca entre as suas componentes físicas e bióticas.

Segundo Ross (1994), as Unidades Ecodinâmicas Instáveis são aquelas cujas intervenções antrópicas modificaram intensamente os ambientes naturais, podendo ser classificadas desde Instabilidade Muito Fraca a Muito Forte.

As Unidades Ecodinâmicas Estáveis são aquelas que estão em equilíbrio dinâmico e foram poupadas da ação humana, podendo apresentar Instabilidade Potencial qualitativamente previsível face as suas características naturais e a possível inserção 
antrópica, recebendo a classificação de Muito Fraca a Muito Forte.

A análise empírica da fragilidade exige estudos básicos do relevo, do subsolo, do solo, do uso da terra e do clima. Os estudos passam pelos levantamentos de campo, pelos serviços de gabinete, a partir dos quais geram-se produtos cartográficos temáticos de geomorfologia, geologia, pedologia, climatologia e uso da terra e cobertura vegetação.

Os estudos do solo permitem avaliar a potencialidade agrícola e a analisar a fragilidade do ambiente face às ações antrópicas ligadas à agropecuária.

Os levantamentos geológicos são básicos para o entendimento da relação relevo/solo/rocha.

Esses estudos, juntamente com a rugosidade topográfica do relevo, as declividades das vertentes e os levantamentos dos tipos de uso da terra, tratados integralmente, possibilitam chegar a um diagnóstico das diferentes categorias hierárquicas da fragilidade dos ambientes naturais.

\footnotetext{
O uso de técnicas de geoprocessamento tem revolucionado 0 planejamento e a gestão ambiental. Os Sistemas de Informações Geográficas permitem a ligação de dados físicos e naturais e dados socioeconômicos, essencial para estudos de planejamento ambiental, como na determinação da vulnerabilidade e fragilidade aos processos erosivos, a partir das unidades da paisagem mapeadas de imagens de satélites (RUHOFF, 2004).
}

O mapa de fragilidade ambiental constitui uma das principais ferramentas utilizadas pelos órgãos públicos na elaboração do planejamento territorial ambiental.

As práticas econômicas predatórias acompanhadas do desperdício dos recursos naturais e a degradação generalizada com perda de qualidade ambiental e de vida requerem, urgentemente, o Planejamento Físico Territorial.

A análise da fragilidade ambiental serve de instrumento para que os planejadores e gestores possam tomar decisões que beneficiem o homem sem degradar o meio ambiente.

Como mencionam Giffoni e Rosa (2007) a sociedade carece de uma visão sistêmica, na qual o homem não seja algo à parte da natureza e sim um membro intimamente ligado e que tem por obrigação demonstrar sustentabilidade ao interagir com a mesma.

\section{Localização da área de estudo}

A área de estudo compreende as seguintes bacias hidrográficas afluentes do Rio Araguari: Bacia Hidrográfica do Córrego Marimbondo, Bacia Hidrográfica do Córrego Terra Branca e Bacia Hidrográfica do Córrego Barrerinha, todas pertencendo ao município de Uberlândia (MG), além de pequenos canais de primeira ordem localizados no município de Araguari (MG). A área está dentro das coordenadas UTM 972600 a 801900 E e 7906900 a 7923400 N (Figura 1). 
Figura 1 - Localização da área de estudo



Essa área está vinculada à evolução geológica da Bacia Sedimentar do Paraná, tendo como unidades morfoesculturais o Planalto Dissecado e o Canyon do Araguari. As rochas predominantes são o arenito da Formação Marília e o basalto da Formação Serra Geral. A vegetação característica é o cerrado, em suas diferentes fitofisionomias. As condições climáticas são definidas por duas estações: uma seca, de abril a setembro, e outra úmida, entre outubro e março. Trata-se de uma área com altitudes entre 570 a 944 metros, sendo que, em sua maior parte, a declividade é de até $12 \%$.

Aproveitando o potencial hídrico da bacia hidrográfica do Rio Araguari, além das usinas hidrelétricas de Nova Ponte e Miranda, foram construídas as usinas de Capim Branco I (Amador Aguiar I) no ano de 2006 e Capim Branco II (Amador Aguiar II) no ano de 2007. Com a formação dos reservatórios, o fundo do vale do Rio Araguari foi totalmente

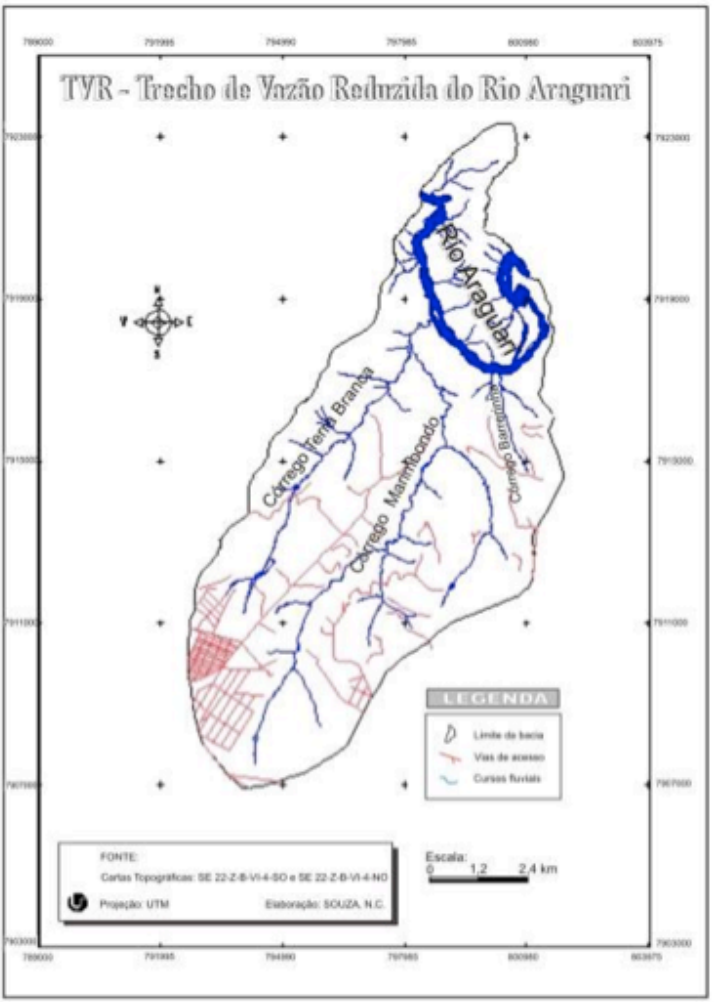

inundado desde sua foz até o remanso na Represa de Nova Ponte, sendo que em uma extensão de mais de 200 km, apenas um trecho de $9 \mathrm{~km}$ preserva as características do canal natural: o Trecho de Vazão Reduzida TVR - do Rio Araguari. O TVR, localizado entre a base do vertedouro da usina de montante até o remanso da usina de jusante, ficou com seu leito natural exposto, recebendo, a montante, uma vazão mínima de $7 \mathrm{~m} 3 / \mathrm{s}$. É neste trecho do Rio Araguari que as bacias hidrográficas aqui estudadas deságuam.

\section{Materiais e métodos}

Para o trabalho, utilizaram-se Cartas Topográficas do Ministério do Exército Departamento de Engenharia e Comunicações - na escala de 1:25.000 (SE 
22-Z-B-VI-4-SO: Cachoeira do Sucupira e SE 22-Z-B-VI-4-NO: Pau Furado), 1984.

Foram utilizadas fotografias aéreas do ano de 1979 na escala de 1:25.000, imagens de Satélite Landsat 5, sensor TM, órbita 221, ponto 073, de 07/07/1999 e 18/07/2009 e mapa do Substrato Rochoso, escala $1: 100.000$, de 1998 .

O software utilizado foi o Spring (Sistema de Processamento de Informações Georeferenciadas) versões 5.0.4 e 5.1.2.

Os trabalhos de campo foram indispensáveis para o conhecimento e estudo da área.

Após o processo de fatiamento da grade altimétrica do terreno foram gerados mapas temáticos. Criou-se o Mapa Hipsométrico e o Mapa de Declividade. Baseando-se em Ross (1994), foram utilizadas as seguintes classes de declividade: $<3 \%$, 3-6\%, 6-12\%, 12-20\%, 20-30\%, 30-
$50 \%$ e >50\%. Também foi elaborado o Mapa Geológico da área de estudo.

Para análise da evolução do uso da terra e cobertura vegetal foram produzidos mapas dos anos de 1979, 1999 e 2009, sendo utilizadas fotografias aéreas e imagens de satélite.

Após a implementação dos diversos produtos intermediários que norteiam a análise da fragilidade ambiental, os mapas de declividade, geologia e uso da terra e cobertura vegetal foram hierarquizados segundo os respectivos códigos de fragilidade para derivação do mapa síntese.

Sete classes de fragilidade foram estabelecidas: muitíssimo fraca (1), muito fraca (2), fraca (3), média (4), forte (5), muito forte (6) e muitíssimo forte (7).

Para as variáveis de declividade e geologia, a fragilidade é maior com o aumento do código (Tabelas 1 e 2 ).

Tabela 1 - Classes de fragilidade para a categoria declividade

\begin{tabular}{ccc}
\hline Fragilidade & Categorias hierárquicas & Código \\
\hline muitíssimo fraca & $<3 \%$ & 1 \\
\hline muito fraca & $3-6 \%$ & 2 \\
\hline fraca & $6-12 \%$ & 3 \\
\hline média & $12-20 \%$ & 4 \\
\hline forte & $20-30 \%$ & 5 \\
\hline muito forte & $30-50 \%$ & 6 \\
\hline muitíssimo forte & $>50 \%$ & 7 \\
\hline
\end{tabular}

Tabela 2 - Classes de fragilidade para a categoria geologia

\begin{tabular}{ccc}
\hline Fragilidade & Categorias hierárquicas & Código \\
\hline fraca & Formação Marília & 3 \\
\hline média & Formação Serra Geral & 4 \\
\hline forte & Grupo Araxá & 5 \\
\hline forte & Embasamento Cristalino & 5 \\
\hline
\end{tabular}


Cinco classes de proteção aos solos pela cobertura vegetal foram estabelecidas: muito alta (2), alta (3), média (4), baixa (5) e muito baixa (6). Para a variável uso do solo e cobertura vegetal os códigos mais altos expressam os menores graus de proteção (Tabela 3).

Tabela 3 - Classes de proteção para a categoria uso da terra/cobertura vegetal:

\begin{tabular}{ccc}
\hline Proteção & Categorias hierárquicas & Código \\
\hline Muito Alta & Mata & 2 \\
\hline Muito Alta & Cerradão & 2 \\
\hline Alta & Cerrado & 3 \\
\hline Média & Pastagem & 4 \\
\hline Média & Agricultura Perene & 4 \\
\hline Baixa & Agricultura Temporária & 5 \\
\hline Muito Baixa & Urbano & 6 \\
\hline
\end{tabular}

Para tratar a relação entre as variáveis declividade, geologia e uso da terra/cobertura vegetal, estabeleceu-se uma classificação da fragilidade a partir de uma associação de dígitos arábicos em que cada um dos números do conjunto numérico representa determinado peso (de 1 a $7=$ do mais fraco ao mais forte; ou do mais protegido ao menos protegido).
Para chegar a um produto cartográfico que identificasse manchas de diferentes padrões de fragilidade potencial, fez-se uma associação numérica das variáveis da categoria geologia (3 a 5) e da categoria declividade (1 a 7). O resultado dessa associação são conjuntos arábicos de dois dígitos que se combinam entre si, podendo haver áreas do tipo 1-3 (variáveis favoráveis) até áreas do tipo 7-5 (todas as variáveis desfavoráveis) (Tabela 4).

Tabela 4 - Combinação das variáveis de geologia e declividade e classificação da fragilidade potencial de acordo com a soma dos dígitos

\begin{tabular}{|c|rr|rr|r|rr|}
\hline \multirow{2}{*}{ Declividade } & \multicolumn{7}{|c|}{ GEOLOGIA } \\
\cline { 2 - 9 } & \multicolumn{2}{|c|}{3} & \multicolumn{2}{|c|}{$\mathbf{4}$} & \multicolumn{2}{|c|}{$\mathbf{5}$} \\
\hline $\mathbf{1}$ & $\mathbf{1}$ & 3 & $\mathbf{1}$ & 4 & $\mathbf{1}$ & 5 \\
\hline $\mathbf{2}$ & $\mathbf{2}$ & 3 & $\mathbf{2}$ & 4 & $\mathbf{2}$ & 5 \\
\hline $\mathbf{3}$ & $\mathbf{3}$ & 3 & $\mathbf{3}$ & 4 & $\mathbf{3}$ & 5 \\
\hline $\mathbf{4}$ & $\mathbf{4}$ & 3 & $\mathbf{4}$ & 4 & $\mathbf{4}$ & 5 \\
\hline $\mathbf{5}$ & $\mathbf{5}$ & 3 & 5 & 4 & 5 & 5 \\
\hline $\mathbf{6}$ & $\mathbf{6}$ & 3 & $\mathbf{6}$ & 4 & $\mathbf{6}$ & $\mathbf{5}$ \\
\hline $\mathbf{7}$ & $\mathbf{7}$ & 3 & $\mathbf{7}$ & $\mathbf{4}$ & $\mathbf{7}$ & $\mathbf{5}$ \\
\hline
\end{tabular}

Chama-se fragilidade potencial a vulnerabilidade natural do ambiente e fragilidade ambiental a vulnerabilidade natural associada ao grau de proteção que exercem os diferentes tipos de uso e cobertura vegetal (KAWAKUBO et al., 2005).

\begin{tabular}{|c|l|c|}
\hline \multicolumn{2}{|c|}{ L E G E N D A } \\
\hline \multicolumn{2}{|c|}{ Fragilidade Potencial } & Soma dos dígitos $=$ \\
\hline \hline & Muito Fraca & 4 e 5 \\
\hline \hline & Fraca & 6 e 7 \\
\hline \hline & Média & 8 \\
\hline & Forte & 9 e 10 \\
\hline & Muito Forte & 11 e 12 \\
\hline
\end{tabular}

Para elaborar o mapa de Fragilidade Potencial foi usado o programa em linguagem Legal (Linguagem Espacial para Geoprocessamento Algébrico) do Spring.

O método usado para produção do Mapa de Fragilidade Ambiental Emergente, 
consistiu em agregar ao Mapa de Fragilidade Potencial as variáveis do uso da terra e cobertura vegetal. Pela associação numérica das variáveis da categoria fragilidade potencial (2 a 6) e da categoria uso da terra e cobertura vegetal (2 a 6), chegou-se à
Tabela 5, constituída da associação numérica de dois dígitos que se combinam entre si, podendo haver áreas do tipo 2-2 (variáveis favoráveis) até áreas do tipo 6-6 (todas as variáveis desfavoráveis).

Tabela 5 - Combinação das variáveis fragilidade potencial e uso/cobertura vegetal

\begin{tabular}{|c|c|c|c|c|c|c|c|c|c|c|}
\hline \multirow{2}{*}{$\begin{array}{c}\text { Uso } \\
\text { da } \\
\text { Terra }\end{array}$} & \multicolumn{10}{|c|}{$\begin{array}{c}\text { FRAGILIDADE POTENCIAL } \\
\text { Combinações dos dígitos }\end{array}$} \\
\hline & & & & & & & & & & \\
\hline 2 & 2 & 2 & 2 & 3 & 2 & 4 & 2 & 5 & 2 & 6 \\
\hline 3 & 3 & 2 & 3 & 3 & 3 & 4 & 3 & 5 & 3 & 6 \\
\hline 4 & 4 & 2 & 4 & 3 & 4 & 4 & 4 & 5 & 4 & 6 \\
\hline 5 & 5 & 2 & 5 & 3 & 5 & 4 & 5 & 5 & 5 & 6 \\
\hline 6 & 6 & 2 & 6 & 3 & 6 & 4 & 6 & 5 & 6 & 6 \\
\hline
\end{tabular}

\begin{tabular}{|c|c|c|c|c|c|}
\hline \multirow{2}{*}{$\begin{array}{c}\text { Uso } \\
\text { da } \\
\text { Terra }\end{array}$} & \multicolumn{5}{|c|}{$\begin{array}{l}\text { FRAGILIDADE POTENCIAL } \\
\text { Soma dos dígitos e Classificação }\end{array}$} \\
\hline & 2 & 3 & 4 & 5 & 6 \\
\hline 2 & 4 & 5 & 6 & 7 & 8 \\
\hline 3 & 5 & 6 & 7 & 8 & 9 \\
\hline 4 & 6 & 7 & 8 & 9 & 10 \\
\hline 5 & 7 & 8 & 9 & 10 & 11 \\
\hline 6 & 8 & 9 & 10 & 11 & 12 \\
\hline
\end{tabular}



Com base nessa classificação e usando a linguagem de programação Legal do Spring, produziram-se os Mapas de Fragilidade Emergente. Os Fluxogramas 1 e 2 mostram, respectivamente, essa sequência de passos e, sinteticamente, as etapas desta pesquisa..

Fluxograma 1 - Passos da construção do Mapa de Fragilidade Emergente

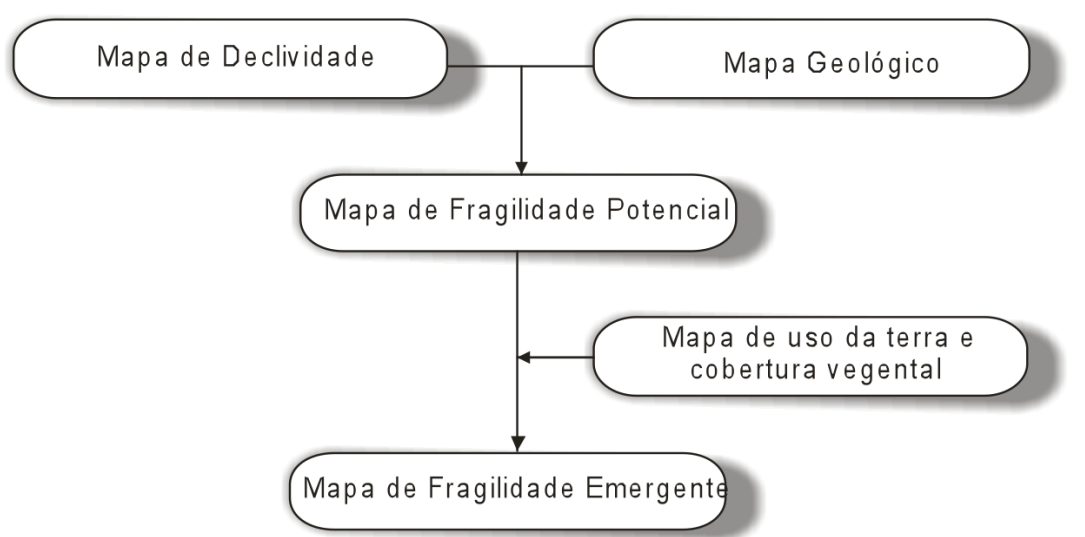


Fluxograma 2 - Etapas da metodologia adotada no trabalho

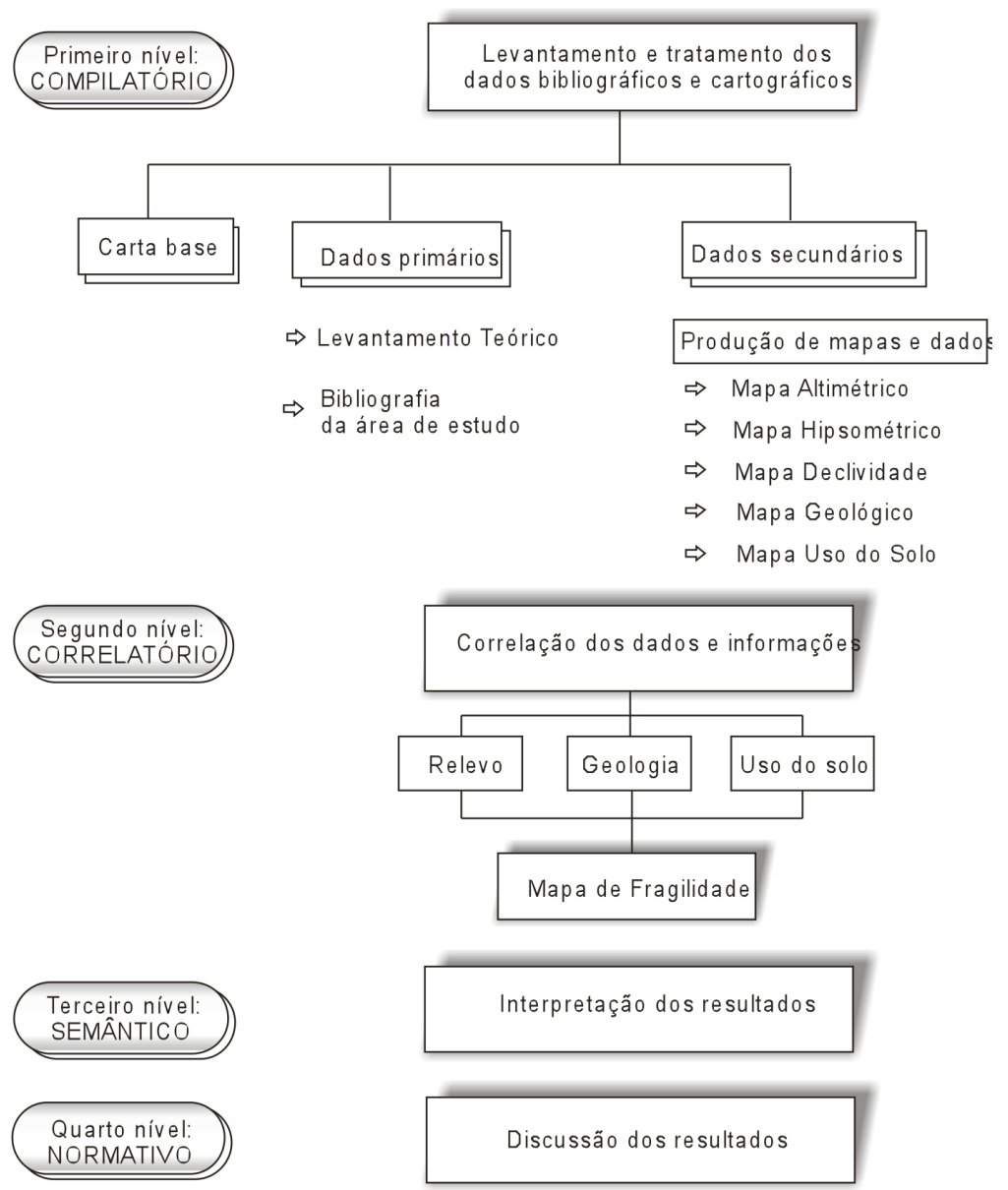

\section{Resultados}

Com ferramentas de

geoprocessamento, foram gerados diversos produtos cartográficos como o Mapa Hipsométrico (Figura 2) e o Mapa Geológico (Figura 3).
Figura 2 - Mapa Hipsométrico



Figura 3 - Mapa Geológico

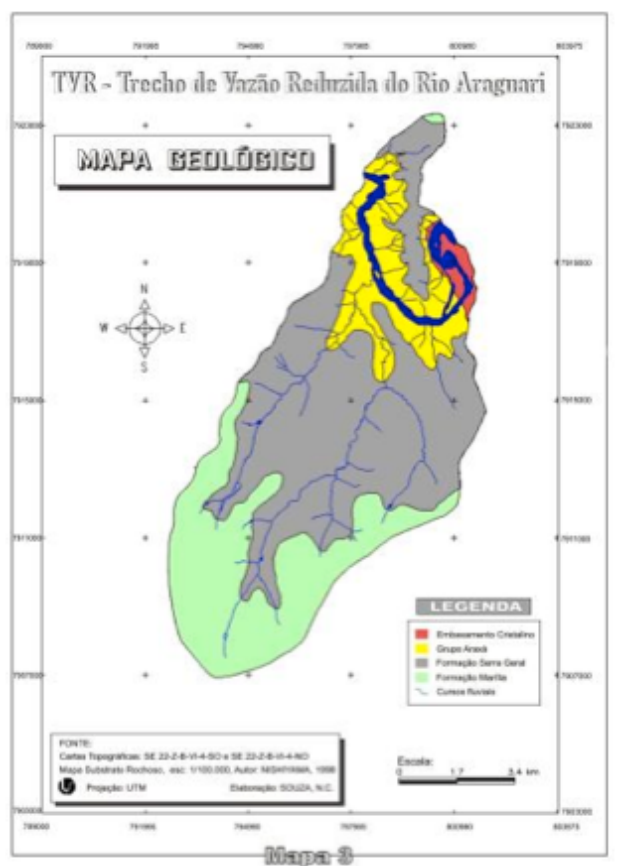


Pelo Mapa de Declividade (Figura 4) e pela Tabela 6 , é possível verificar que

Figura 4 - Mapa de Declividade

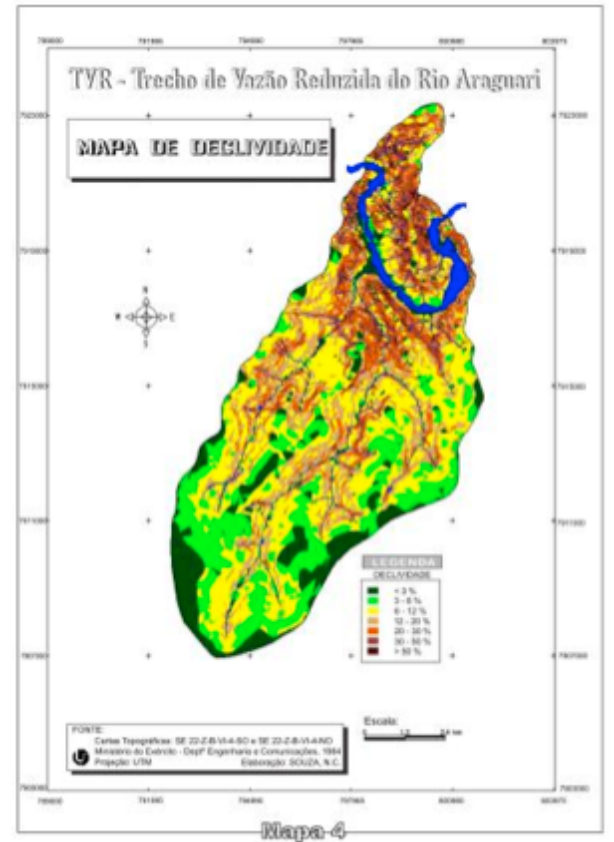

Com as variáveis de declividade e geologia, criou-se o Mapa de Fragilidade Potencial (Figura 5), que, com a Tabela 7, permitem verificar que a maior parte da área apresenta uma Fragilidade Potencial fraca ou

Figura 5 - Mapa de Fragilidade Potencial

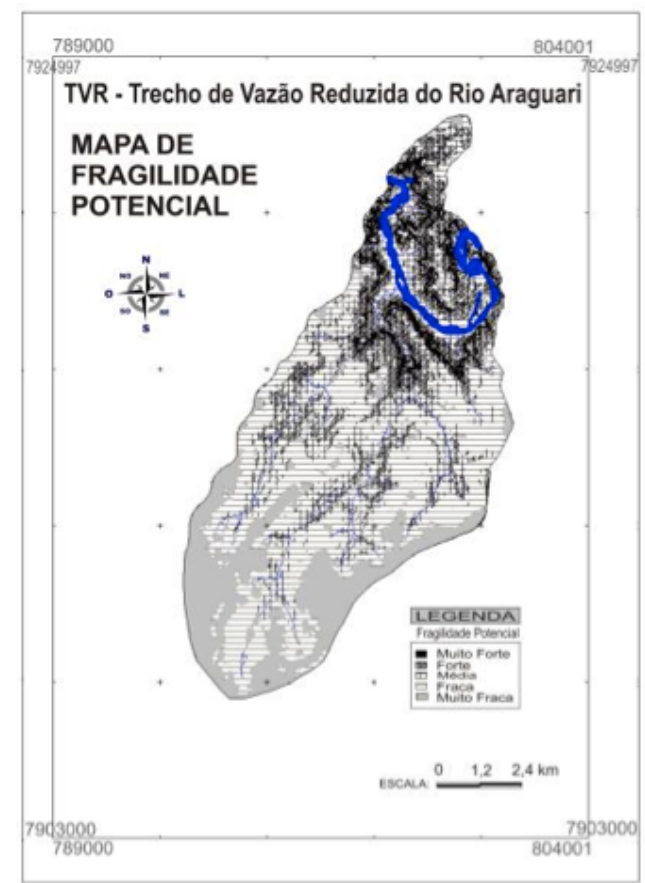

$62,49 \%$ da área tem declividade inferior a $12 \%$.

Tabela 6 - Área e porcentagem das faixas de declividade do terreno

\begin{tabular}{ccc}
\hline $\begin{array}{c}\text { Faixas de } \\
\text { declividade }\end{array}$ & Área $\left(\mathrm{km}^{2}\right)$ & $\%$ \\
\hline$<3 \%$ & 9,69 & 12,26 \\
$3-6 \%$ & 15,82 & 20,01 \\
$6-12 \%$ & 23,89 & 30,22 \\
$12-20 \%$ & 15,80 & 20,00 \\
$20-30 \%$ & 7,84 & 9,92 \\
$30-50 \%$ & 5,17 & 6,55 \\
$>50 \%$ & 0,83 & 1,04 \\
\hline TOTAL & 79,04 & 100,00 \\
\hline
\end{tabular}

muito fraca. um dos motivos que levam a essa classificação é a baixa declividade do relevo que contribui para inibir os processos de escoamento superficial e aumentar a infiltração de água pelo solo.

Tabela 7 - Área e porcentagem das categorias de fragilidade potencial

\begin{tabular}{ccc}
\hline $\begin{array}{c}\text { Fragilidade } \\
\text { potencial }\end{array}$ & Área $\left(\mathrm{km}^{2}\right)$ & $\%$ \\
\hline muito fraca & 16,86 & 21,32 \\
fraca & 31,14 & 39,36 \\
média & 14,50 & 18,32 \\
forte & 13,14 & 16,60 \\
muito forte & 3,48 & 4,40 \\
\hline TOTAL & 79,12 & 100,00 \\
\hline
\end{tabular}


Para chegar à Fragilidade Emergente de um ambiente, é preciso associar a sua vulnerabilidade natural os diferentes tipos de uso e cobertura vegetal. Para isso, foram elaborados os Mapas de Uso da Terra e Cobertura Vegetal dos anos de 1979, 1999 e 2009 (Figura 6). Nesse período de 30 anos, foi possível analisar a evolução de cada categoria de uso da terra: a cobertura vegetal crescimento $172 \%$ (Tabela 8) e ocupa principalmente as áreas de maior declividade. O crescimento dessa categoria pode ser explicado pelo cumprimento da legislação ambiental no tocante às áreas de Reserva Legal e de Preservação Permanente. Além da determinação legal, outro fator determinante é o novo paradigma ambiental, em que a exploração desenfreada dos recursos naturais cede passo à preservação ambiental. Exemplo disso é o Parque Estadual do Pau Furado, criado em janeiro de 2007, como medida compensatória pela construção das hidrelétricas do consórcio Capim Branco Energia.

No mesmo período, verificou-se o desaparecimento das áreas de cerrado, substituídas por pastagem, agricultura e área urbana. O total da área de pastagem diminuiu 19,74\%, tendo sido substituída principalmente pela agricultura.

Entre 1979-2009, a área urbana cresceu 209\%. Em virtude do mercado imobiliário e da construção do anel viário de Uberlândia, a tendência é a área urbana continuar aumentando.

Figura 6 - Mapas de uso da terra e cobertura vegetal

\section{Evolução do Uso da terra e Cobertura Vegetal no Trecho de Vazão Reduzida do Rio Ar}

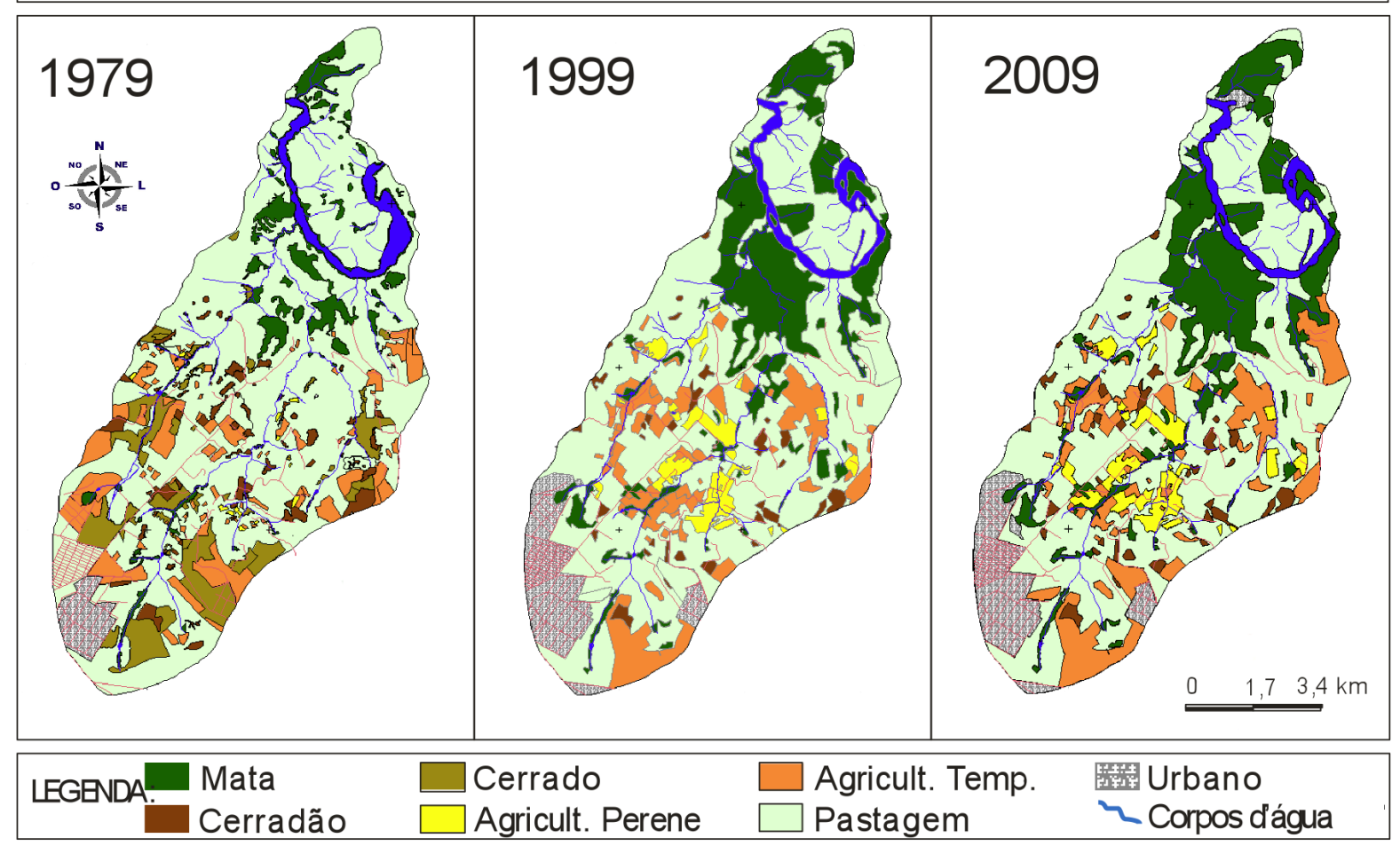


Tabela 8 - Área e porcentagem das categorias uso da terra e cobertura vegetal nos anos de 1979, 1999 e 2009

\begin{tabular}{|c|c|c|c|c|c|c|}
\hline \multicolumn{7}{|c|}{ Uso da terra e cobertura vegetal } \\
\hline \multirow{2}{*}{ Categoria } & \multicolumn{2}{|c|}{1979} & \multicolumn{2}{|c|}{1999} & \multicolumn{2}{|c|}{2009} \\
\hline & $\mathbf{k m} \mathbf{2}^{2}$ & $\%$ & $\mathbf{k m} \mathbf{m}^{2}$ & $\%$ & $\mathbf{k m} \mathbf{m}^{2}$ & $\%$ \\
\hline Mata & 5,30 & 6,89 & 13,60 & 17,68 & 14,44 & 18,79 \\
\hline Cerradão & 2,55 & 3,32 & 1,68 & 2,19 & 1,79 & 2,33 \\
\hline Cerrado & 7,20 & 9,37 & 0 & 0,00 & 0 & 0,00 \\
\hline Agricultura Perene & 0,21 & 0,27 & 1,96 & 2,55 & 3,54 & 4,60 \\
\hline Agricultura Temporária & 7,05 & 9,17 & 7,96 & 10,36 & 9,19 & 11,95 \\
\hline Pastagem & 52,76 & 68,64 & 46,43 & 60,40 & 42,34 & 55,08 \\
\hline Urbano & 1,80 & 2,34 & 5,24 & 6,82 & 5,57 & 7,25 \\
\hline Total $^{(*)}$ & 76,87 & 100 & 76,87 & 100 & 76,87 & 100 \\
\hline
\end{tabular}

${ }^{(*)}$ A área total não incluiu os corpos d'água.

Como produtos cartográficos sínteses, elaboraram-se os Mapas de Fragilidade
Emergente dos anos de 1979, 1999 e 2009

(Figura 7).

Figura 7 - Mapas de Fragilidade Emergente

Fragilidade Emergente no Trecho de Vazão Reduzida do Rio Araguari (1979, 1999 e 2009)

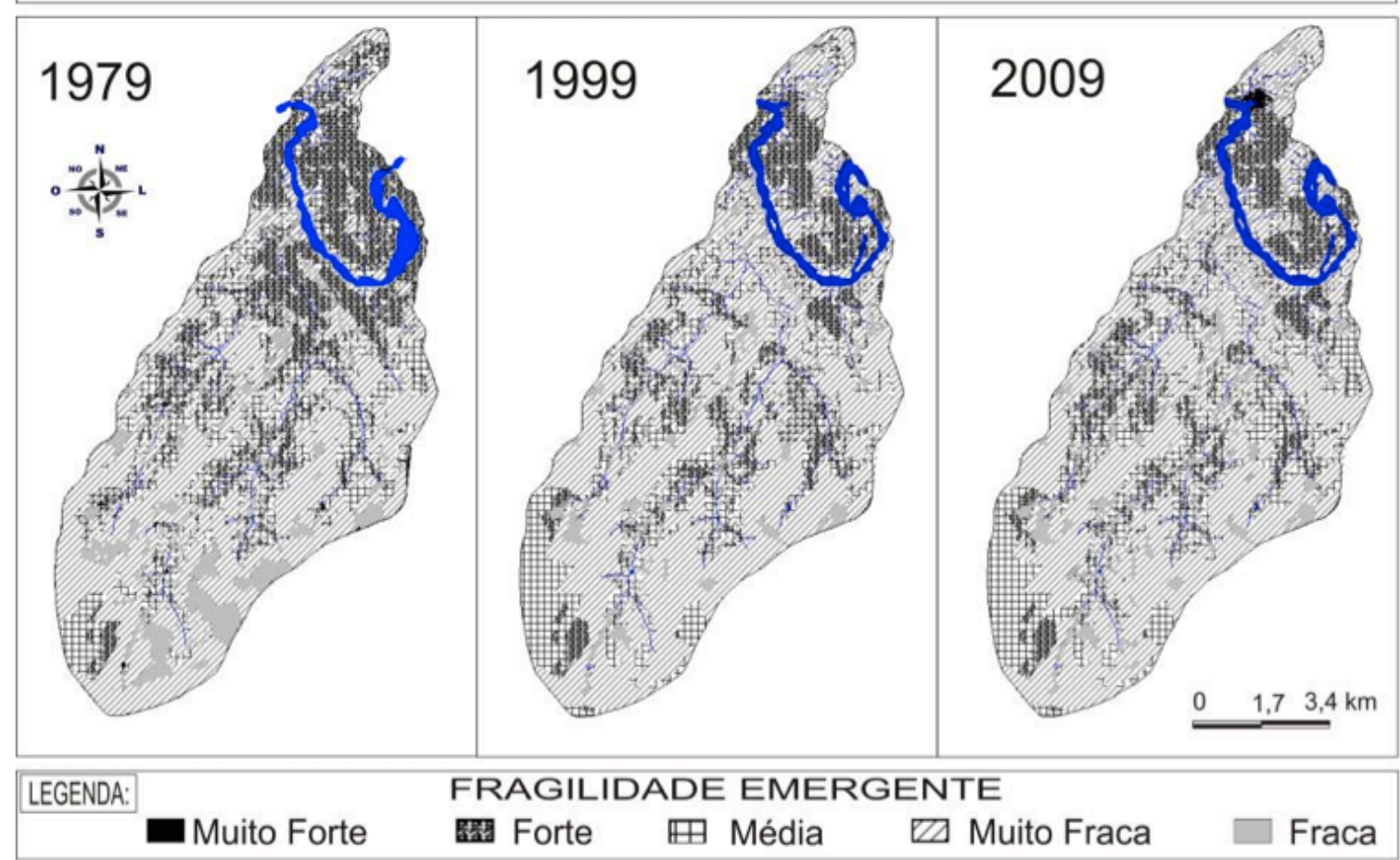

Na Tabela 9, percebe-se que predomina a fragilidade ambiental fraca. Um dos fatores determinantes é a baixa declividade do relevo.

A maior fragilidade é encontrada nas áreas onde a declividade é maior, e a maioria delas está perto das margens do Rio Araguari e dos córregos.
A categoria fragilidade muito fraca diminui no período, entre outras causas, pelo crescimento urbano e pela substituição das áreas de cerrado por agricultura e pastagem.

O crescimento da categoria fragilidade média pode ser explicado, em sua maior parte, pelo aumento da área urbana. 
A categoria fragilidade forte diminuiu no período analisado, e essa diminuição está ligada ao aumento da cobertura vegetal de mata nas áreas de maior fragilidade.

Tabela 9 - Área e porcentagem das categorias fragilidade ambiental emergente com as variáveis uso da terra e fragilidade potencial

\begin{tabular}{ccccccc}
\hline \multirow{2}{*}{$\begin{array}{c}\text { Fragilidade } \\
\text { Emergente }\end{array}$} & \multicolumn{2}{c}{$\mathbf{1 9 7 9}$} & \multicolumn{2}{c}{$\mathbf{1 9 9 9}$} & \multicolumn{2}{c}{$\mathbf{2 0 0 9}$} \\
\cline { 2 - 7 } & Área $\left(\mathrm{km}^{2}\right)$ & $\%$ & Área $\left(\mathrm{km}^{2}\right)$ & $\%$ & Área $\left(\mathrm{km}^{2}\right)$ & $\%$ \\
\hline muito fraca & 6,67 & 8,68 & 3,66 & 4,76 & 4,6 & 5,98 \\
fraca & 39,15 & 50,93 & 45,17 & 58,76 & 41,47 & 53,95 \\
média & 17,1 & 22,25 & 18,63 & 24,24 & 20,59 & 26,79 \\
forte & 13,92 & 18,11 & 9,39 & 12,22 & 10,03 & 13,05 \\
muito forte & 0,03 & 0,04 & 0,02 & 0,03 & 0,18 & 0,23 \\
\hline TOTAL & 76,87 & 100,00 & 76,87 & 100,00 & 76,87 & 100,00 \\
\hline
\end{tabular}

As Fotos 1 e 2 mostram que, apesar do intenso uso antrópico, ainda é possível

Foto 1 - Resquício de vegetação original

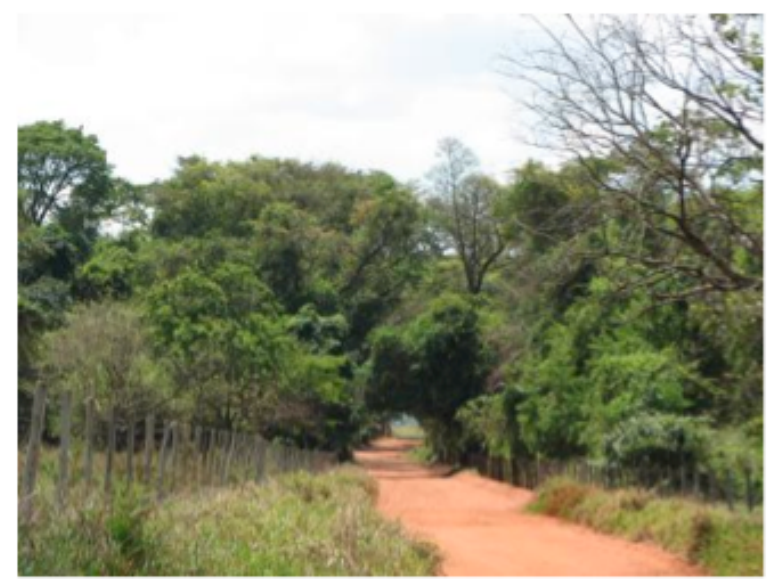

As Fotos 3 e 4 apresentam a situação de dois cursos d'água, um que permaneceu com suas condições naturais intactas ou

Foto 3 - Cachoeira do Marimbondo

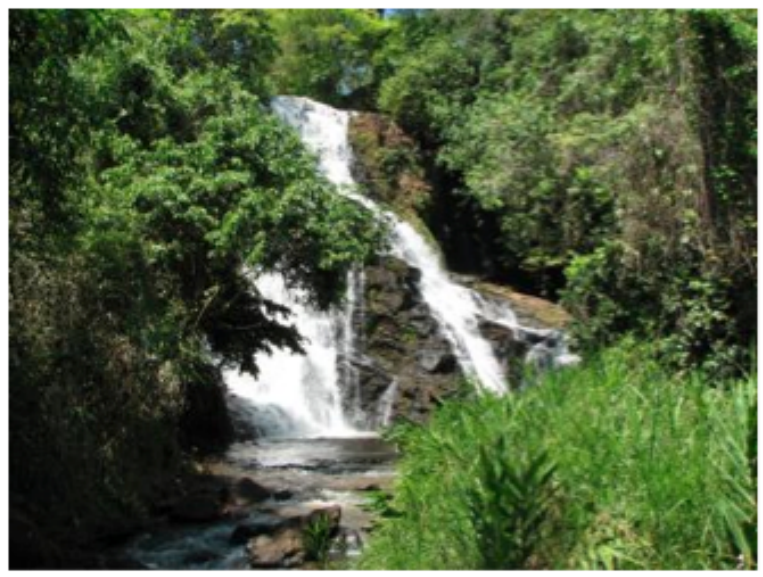

A categoria fragilidade muito forte é maior no ano de 2009, devido à construção da Usina Hidrelétrica Capim Branco I. encontrar áreas com resquícios de cobertura vegetal original.

Foto 2 - Atividade agrícola - culturas perenes

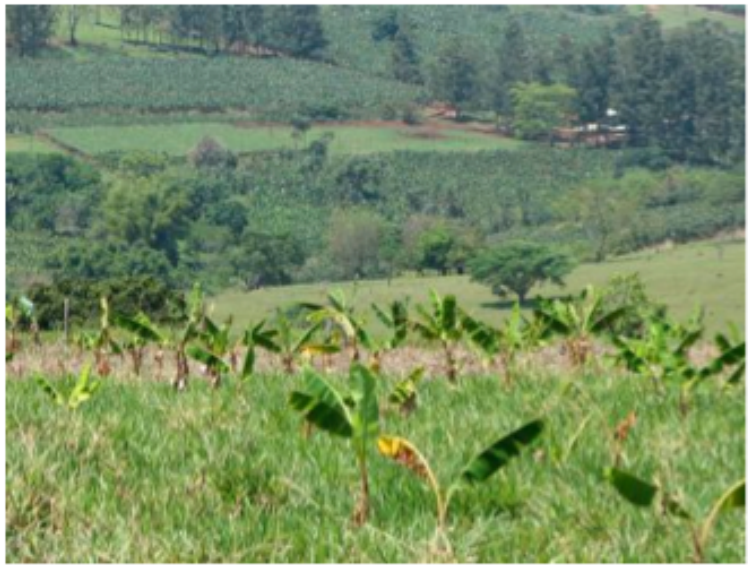

pouco alteradas e outro que sofreu a interferência do homem, tendo sua vazão alterada para gerar energia elétrica.

Foto 4 - Vazão reduzida do Rio Araguari

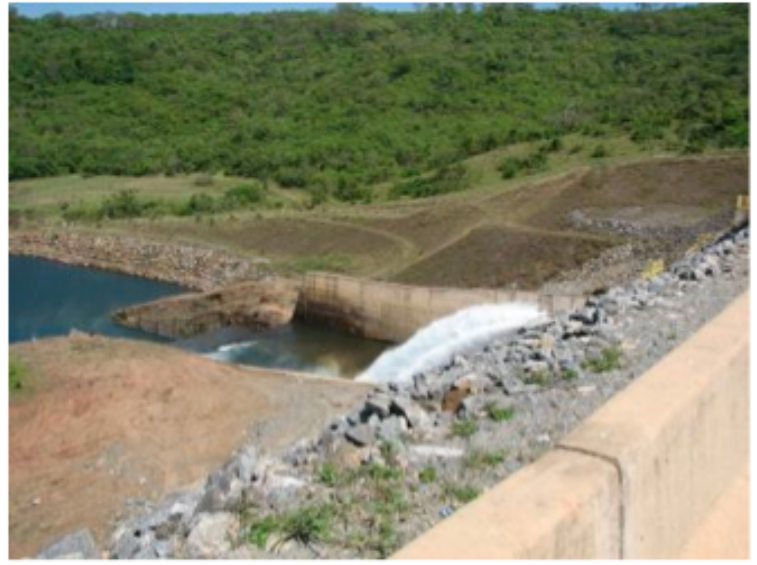


Comparando o presente trabalho com o de Oliveira (2006), que estudou a Bacia Hidrográfica do Córrego Pindaíba, contígua e com características semelhantes à do Córrego Marimbondo, pode-se verificar que o método adotado aqui logrou apresentar mais detalhes. Outra diferença foi a forma de apresentar todas as áreas de fragilidade em um único mapa, enquanto que Oliveira (2006) elaborou para cada tipo de categoria de fragilidade um mapa respectivo.

\section{Considerações finais}

Os resultados mostraram a eficácia dos sistemas computacionais na análise empírica da fragilidade ambiental.

As técnicas de geoprocessamento foram fundamentais para a geração dos mapas de Fragilidade Potencial e Fragilidade Emergente, uma vez que a geração destes se deve a sobreposição dos mapas temáticos armazenados no sistema de geoprocessamento Spring.
Além das variáveis consideradas no presente trabalho, deve-se ainda levar em conta as práticas agrícolas. As práticas agrícolas conservacionistas, como o manejo dos solos para a agricultura, são fatores essenciais para conter os processos erosivos. Com a soma de todas essas variáveis é possível chegar ao diagnóstico da fragilidade ambiental do TVR do Rio Araguari. Esse diagnóstico é uma ferramenta que pode contribuir como subsídio aos estudos de planejamento ambiental.

Verifica-se que essa área sofre a pressão do avanço da ocupação urbana. Há que considerar o crescimento urbano e agrícola nessa área e promover políticas e ações que avaliem os impactos da ação antrópica no meio ambiente.

Dessa forma será possível aproveitar os recursos e potencialidades dessa área sem, contudo, chegar à degradação do ecossistema.

\section{Referências bibliográficas}

BACCARO, C. A. D.; MEDEIROS, S. M.; FERREIRA, I. L.; RODRIGUES, S. C. Mapeamento geomorfológico da Bacia do Rio Araguari (MG). In: LIMA, S. C.; SANTOS, R. J. (Orgs.). Gestão ambiental da Bacia do Rio Araguari: rumo ao desenvolvimento sustentável. Brasília: CNPq/UFU/IG, 2004.

BRASIL. Ministério do Exército. Diretoria de Serviço Geográfico. Carta Militar. Folhas SE 22-Z-B-VI-4-NO, SE 22-ZB-VI-4-SO, Brasília, 1983, Escala $1: 25.000$.

BRITTO, C. Q. Zoneamento ambiental do Parque Estadual do Rio Doce (MG) segundo o grau de qualidade dos biótopos. Dissertação (Mestrado em Geografia)
- Universidade Federal de Uberlândia, Uberlândia, 2004.

BRITO, J. L. S. Adequação das potencialidades do uso da terra na Bacia do Ribeirão Bom Jardim no Triângulo Mineiro (MG): ensaio de geoprocessamento. Tese (Doutorado em Geografia) Faculdade de Filosofia, Letras e Ciências Humanas, Universidade de São Paulo, São Paulo, 2001.

CARRIJO, B. R. As usinas hidrelétricas e as alterações na dinâmica da Bacia do Rio Araguari - MG.

Dissertação (Mestrado em Geografia) - Universidade Federal de Uberlândia, Uberlândia, 2002.

GIFFONI, S. N.; ROSA, R. Mapeamento dos remanescentes da cobertura vegetal 
natural do município de Uberlândia no ano de 2002. In: SIMPÓSIO BRASILEIRO DE SENSORIAMENTO REMOTO. XIII, 2007, Florianópolis. Anais... Florianópolis: INPE, 2007. p. 1679-1686.

INSTITUTO NACIONAL DE PESQUISAS ESPACIAIS. INPE. Introdução ao Spring: Tutorial. São José dos Campos: Instituto Nacional de Pesquisas Espaciais, 2008.

INSTITUTO NACIONAL DE PESQUISAS ESPACIAIS (INPE) - SPRING Sistema de Processamento de Informações Georeferenciadas. Disponível em $<$ http://www.dpi.inpe.br/spring/portu gues/index.html>. Acesso em: 18 nov. 2009.

KAWAKUBO, F. S. et al. Caracterização empírica da fragilidade ambiental utilizando geoprocessamento. In: SIMPÓSIO BRASILEIRO DE SENSORIAMENTO REMOTO, XII, 2005, Goiânia. Anais... Goiânia: INPE, 2005. p. 2203-2210.

LIBAULT, A. Os quatro níveis da pesquisa geográfica. Métodos em questão. São Paulo: USP/IG, 1971.

NISHIYAMA, L. Procedimentos de mapeamento geotécnico como base para análise e avaliação do meio físico em escala 1:100.000. Aplicação no município de Uberlândia. Tese (Doutorado) - Escola de Engenharia de São Carlos, Universidade de São Paulo, São Paulo, 1998.

OLIVEIRA, P. C. A. Diagnóstico ambiental e análise da fragilidade do relevo da Bacia Hidrográfica do Córrego Pindaíba - Uberlândia (MG). Monografia (Bacharel em Geografia) Instituto de Geografia, Universidade Federal Uberlândia, Uberlândia, 2006.

RODRIGUES, S. C. Mudanças ambientais na região do cerrado. Análise das causas e efeitos da ocupação e uso do solo sobre o relevo. O caso da Bacia Hidrográfica do Rio Araguari, MG. GEOUSP - Espaço e Tempo, São Paulo, n. 12, p. XX, 2002.
RODRIGUES, S. C.; FERREIRA, I. L.; MEDEIROS, S. M.; BACCARO, C. A. D. Cartografia geomorfológica e os condicionantes hidrogeomorfológicos de erosão em áreas amostrais da Bacia Hidrográfica do Rio Araguari. In: LIMA, S. C.; SANTOS, R. J. (Orgs.). Gestão ambiental da Bacia do Rio Araguari: rumo ao desenvolvimento sustentável, UFU/IG, 2004.

ROSA, R.; BRITO, J. L. S. Introdução ao geoprocessamento: sistema de informação geográfica. Uberlândia, 1996.

ROSENDO, J. S. Índices de vegetação e monitoramento do uso do solo e cobertura vegetal na Bacia do Rio Araguari - MG - utilizando dados do sensor modis. Dissertação (Mestrado em Geografia) Universidade Federal de Uberlândia, Uberlândia, 2005.

ROSS, J. L. S. Análise empírica da fragilidade dos ambientes naturais e antropizados. Revista Departamento Geografia, São Paulo: USP, p. 63-74, 1994.

RUHOFF, A. L. Gerenciamento de recursos hídricos em bacias hidrográficas: modelagem ambiental com a simulação de cenários preservacionistas. Dissertação (Mestrado em Geomática) Universidade Federal de Santa Maria, Santa Maria, 2004.

SCHNEIDER, M. J.; BELLON, O. R. P.; ARAKI, $H$. Experimentos em fusão de imagens de alta resolução. Boletim de Ciências Geodésicas, Curitiba, v. 9, n. 1, p. 75-88, 2003.

SILVA, A. M.; PINHEIRO, M. S. F.; FRANÇA, M. N. Guia para normalização de trabalhos técnico-científicos: projetos de pesquisa, trabalhos acadêmicos, dissertações e teses. 5. edição. Uberlândia: EDUFU, 2006.

TRICART, J. Ecodinâmica. Rio de Janeiro: FIBGE, 1977. 